\title{
The Herd Health Handbook for Goat Producers: Food Safety at the Farm Gate: A Holistic Approach to Food Safety and Herd Health ${ }^{1}$
}

Ray Mobley and Carmen Lyttle-N'guessan ${ }^{2}$

\section{Introduction}

The outlook of food safety has changed in the last 15 years. The earlier emphasis was at the processor, retail, and consumer levels, which has shifted as more is learned about detection, prevention, and control strategies. The entire food chain and each station recognized the responsibility of ensuring safety of the product.

Prior to the early 1990 s, the food safety program was driven by sanitation codes, which were enacted during the early 1900s. These codes relied on the senses of touch, smell and taste and environmental conditions as an indicator of the safety of foods. These were applied after the product was produced, and placed the food safety responsibility on processors, manufacturers, and retailers. The emphasis has shifted to a science-based preventive strategy where all sectors in the food chain are responsible for the safety and integrity of the food supply. Increased emphasis is now being given to on-farm programs.

Food-borne pathogens arrive to processors with the raw product in many instances. The farm-to-table strategy recognizes the importance of producers providing preventive and control measures that will minimize the risk to processors, food handlers, and consumers, who eventually get the product. A succinct and detailed producer-level food safety program also enhances the cost efficiency, and impacts herd health at the farm level.

\section{A Model Producer Food Safety Program}

The basic tenets of food safety apply to producers as much as they do to other handlers of food products. An effective food safety program need not be overly complicated, unrealistic, or impossible to implement. It should target the important areas where hazards can be controlled such as packaging, food storage, processing, food sanitation and handling, farm sanitation and farm traffic. Targeting crucial areas of food safety or food safety risks is the key to a successful program. Applying concentrated attention in a manner which allows for the control of those risks is at the core of a preventive based on farm/pre-harvest food safety program. In order to determine these strategic areas, producers can rely on experience, local, state, and federal regulatory information, as well as academia, and industry guidance.

\section{What is the Aim for a Food Safety Program?}

A food safety program for producers must be aimed at the control of identified significant hazards. A hazard is an entity that renders a product unsafe for consumption.

\section{Categories of Food Safety Hazards}

1. Biological Hazards: Examples of biological hazards are bacteria, viruses, parasites, fungi, yeasts and molds. Bacteria are responsible for the majority of food-borne illnesses and constitute the most important category of on-farm

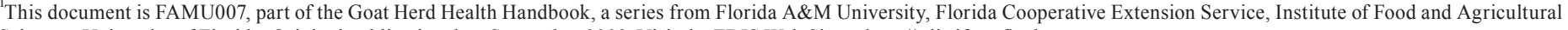
Sciences, University of Florida. Original publication date September 2009. Visit the EDIS Web Site at http://edis.ifas.ufl.edu.

${ }^{2}$ Ray Mobley, director, Cooperative Extension; Carmen Lyttle-N'guessan, veterinary care manager; Florida A\&M University, College of Engineering Sciences, Technology and Agriculture, Cooperative Extension Programs; Florida Cooperative Extension Service, Institute of Food and Agricultural Sciences, University of Florida, Gainesville, FL 32611.

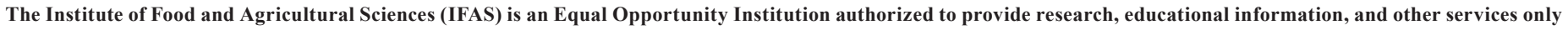

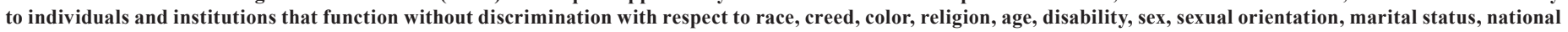

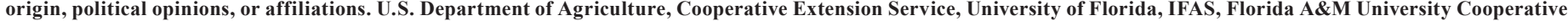
Extension Program, and Boards of County Commissioners Cooperating. Millie Ferrer-Chancy, Interim Director
} 
hazards. Most biological hazards can survive under ideal conditions on the farm, but can be controlled through good sanitation, bio-security and environmental control measures.

2. Chemical Hazards: Chemical hazards consist of products or by-products of substances used on the farm such as medications and drugs, pesticides, herbicides, and feed additives. Human risk of chemical exposure includes hypersensitivity or allergic reactions, and increased risks to carcinogens. Observing prescribed withdrawal times for therapeutic antibiotics can avoid exposure to residues in medicated animals. Chemical exposure can also be controlled by the safe application of pesticides and other chemicals in accordance with label instructions, and keeping animals away from exposed chemical applications. Medications should also be applied in accordance with label instructions, and as recommended by professionals. Controlling the chemicals used in animals will often prevent the human exposure of these hazards.

3. Physical Hazards: Physical hazards are inanimate objects that cause physical injury or insult. These include metal, needles, wood, wire, etc. Physical hazards usually result in injury to an individual consumer involving a broken tooth, cut mouth, or choking. These hazards can be prevented or controlled on the farm by using good quality assurance measures, good fencing and repair practices and control of the intentional or unintentional shooting of food animals.

A sound producer food safety program should incorporate good sanitation and agricultural practices. Conditions that can typically be addressed in an on-farm sanitation program include the safety of water, feed storage, disposal of manure, pest control, and disposal of dead stock. Other elements of a solid program should include bio-security and quality assurance measures.

\section{Conclusion}

The framework of a HACCP-based food safety program is possible at the producer level. Although it will require modifications, its implementation can enhance a farm-to-table approach to food safety and increase the confidence of customers purchasing producer products. This system can also make the man- agement of herd health and other concerns much more user-friendly. Producers are expected to know the role they play in combating food-borne illnesses. Using a sound science-based program will enhance the total food safety approach and give increased credibility to on-farm management programs.

\section{References}

Merck \& Company, Inc. (2008). Biosecurity: Goats. The Merck Veterinary Manual, http://www. merckvetmanual.com/mvm/index.jsp, Received July 22, 2009

Steveson, K. E., \& Bernard, D. T. (1995). Establishing hazard analysis critical control point program: A workshop manual 2nd ed. The food processors institute 1350 I Street, N.W., Suite 300 Washington, D. C. 20005-3305. 